\title{
Fra aktiv og passiv dødshjelp til eutanasi og behandlingsbegrensning
}

\author{
Begrepene aktiv dødshjelp og passiv dødshjelp bør ikke lenger benyttes. De er upresise og har flere uheldige \\ konnotasjoner. I stedet foreslår vi en kombinasjon av nederlandsk begrepsbruk og et nyere norsk begrep.
}

\section{Lars Johan Materstvedt}

lars.johan.materstvedt@ntnu.no

Filosofisk institutt

Norges teknisk-naturvitenskapelige universitet

Reidun Førde

Senter for medisinsk etikk

Universitetet i Oslo

Aktiv dødshjelp er et velkjent begrep. Det brukes i Legeforeningens Etiske regler for leger (1), i juridisk litteratur (2), og det forekommer i mediene. Det hersker imidlertid stor forvirring når det gjelder begrepene aktiv og passiv dødshjelp. Dette resulterer ikke sjelden i enten skinnuenighet eller skinnenighet (3). En åpenbar grunn til ikke å bruke begrepene er at aktiv og passiv ikke er dekkende for hva som faktisk skjer. «Passiv dødshjelp» kan kreve aktiv handling, like aktiv som den «aktive dødshjelpen». At det skal være et klart moralsk skille mellom disse to basert på aktivitet alene, er derfor ikke umiddelbart logisk. $\AA$ avslutte respirasjonsstøtte til en pasient med amyotrofisk lateral sklerose i terminalfasen, med den følge at han dør, er noe de fleste antakelig vil finne moralsk akseptabelt. Men fordi det her er snakk om en aktiv handling, er det ikke urimelig å tro at mange vil anse dette som en form for legitim aktiv dødshjelp.

\section{Problemer med begrepet «dødshjelp»}

Er det dødshjelp å innstille aggressiv kjemoterapi hos en døende kreftpasient av hensyn til dennes livskvalitet i livets sluttfase? Klinikere vil ventelig svare et klart «nei». Det samme gjør Legeforeningen: «Å avslutte eller ikke sette i gang hensiktsløs behandling, er ikke å regne som aktiv dødshjelp» (1). Vi mener at dette heller ikke skal ha merkelappene «passiv» eller «dødshjelp» slik det kalles av mange i dag. Man begrenser behandling med liten nytte og potensial for å skade. Av denne grunn har vi annetsteds foreslått å kalle slike handlinger «behandlingsbegrensning» (4). En bestemt klinisk intervensjon seponeres, men man fortsetter med symptomlindrende tiltak helt frem til dødstidspunktet. Derfor er begrepene «behandlings- avslutning» og «behandlingsunnlatelse» også uheldig å bruke, ettersom de impliserer at ingen behandling gis overhodet. Unnlatelse kan dessuten forstås som noe moralsk problematisk (4). I eksempelet med kreftpasienten ville det derimot være moralsk problematisk å fortsette med invasiv behandling.

Et sentralt argument for at legen skal ha lov til å hjelpe en pasient med å dø er prinsippet om selvbestemmelse. Det er imidlertid uklart hvorvidt aktiv dødshjelp innebærer at det foreligger en kompetent forespørsel fra pasienten. Følgelig kan begrepet dekke både frivillige, ufrivillige og ikke-frivillige former (4). En nyere, representativ undersøkelse av norske legers praksis, utført av Førde og medarbeidere (5), er heller ikke klar på dette punktet fordi man ikke spurte om det forelå et eksplisitt ønske fra pasienten. Etiske regler for leger omhandler ikke denne tematikken, ettersom $\S 5$ begrenser seg til følgende formulering: «Aktiv dødshjelp, dvs. tiltak som har til hensikt å fremskynde en pasients død, må ikke anvendes» (1).

\section{Den nederlandske forståelsen}

«Aktiv/passiv dødshjelp» tilsvarer «active/ passive euthanasia» (4). Den nederlandske legen, medisinske etikeren, og kjente eutanasitilhengeren og -praktikeren Gerrit Kimsma påpekte for mange år siden at «termen passiv eutanasi brukes ikke lenger i Nederland» (6), og at den er «utdatert og innebærer en motsigelse» (7). Eutanasi er per defininsjon en aktiv handling: Legen setter dødelige injeksjoner, på pasientens eksplisitte forespørsel $(8,9)$. De store nederlandske, nasjonale studiene av legers praksis utført i 1990, 1995, 2001 og 2005 benytter denne forståelsen, og man finner ikke begrepet «passiv eutanasi» i noen av disse studiene $(8,9)$. The European Association for Palliative Care (EAPC) (10) definerer eutanasi i tråd med nederlandsk teori og praksis som «En leges intenderte drap på en person ved å injisere medikamenter, på personens frivillige og kompetente forespørsel» (11).

Nå vil det kunne innvendes at «drap»er et ledende ord; hvem vil vel forsvare drap? Men i Nederland forstås eutanasi nettopp som «drap på forespørsel». Den ameri- kansk-nederlandske jusprofessoren og eutanasiforkjemperen John Griffiths og medarbeidere skriver i et kjent standardverk (12):

««Euthanasia» in the strict - and in the

Dutch context the only proper - sense refers to the situation in which a doctor kills a person who is suffering «unbearably» and «hopelessly» at the latter's explicit request (usually by administering a lethal injection). ... «euthanasia» is in the Netherlands reserved for killing on request.»

En parallell oppfatning finner man for øvrig i norsk straffelov. I §235, som vil ramme tilfeller av eutanasi (2), heter det: «Er nogen med eget Samtykke dræbt» (13). I en kvalitativ studie av nederlandske primærlegers opplevelse av å utføre eutanasi beskriver endog en lege seg selv som «bøddel» (14).

Selv om eutanasi teknisk sett er å drepe ved å gjennomføre en bestemt prosedyre, er det ikke dermed sagt at dette etisk sett bør vurderes som forkastelig - eller at det ikke bør det. Det er her viktig å holde to aspekter fra hverandre: Hva noe faktisk «er», og hvorvidt dette som er, også «bør» være. Denne forskjellen mellom det empiriske og det normative representerer et klassisk skille innen etikken og stammer fra filosofen David Hume (1711-76). Hume påpekte at man ikke kan slutte fra er til bør; mange gjør det - eller rettere: tror det går an - og begår dermed den såkalte naturalistiske feilslutning (15). For å kunne ta stilling til moraliteten av eutanasi, må man blant annet ty til etisk teori som analyseverktøy. Her finnes et vell av ulike syn, og forskjellige teorier vil generere forskjellige og også motstridende konklusjoner (16).

\section{Eutanasi og legeassistert selvmord} Eutanasi er lovlig i Nederland, Belgia og Luxembourg. Det sies og skrives ofte, også $\mathrm{i}$ internasjonale tidsskrifter, inkludert av nederlandske forfattere, at eutanasi fortsatt er forbudt i Nederland (17), men at legen kan «slippe unna» ved å følge visse retningslinjer og med henvisning til nødrettsparagrafen i straffeloven. Det er ikke korrekt. Slik var situasjonen fra 1984 til 1.4. 2002 (18). Da trådte en lov (19) i kraft som fullt ut legaliserer eutanasi på visse betingelser (20). Det er dessuten en utbredt misforståelse at pasienten må være terminalt 


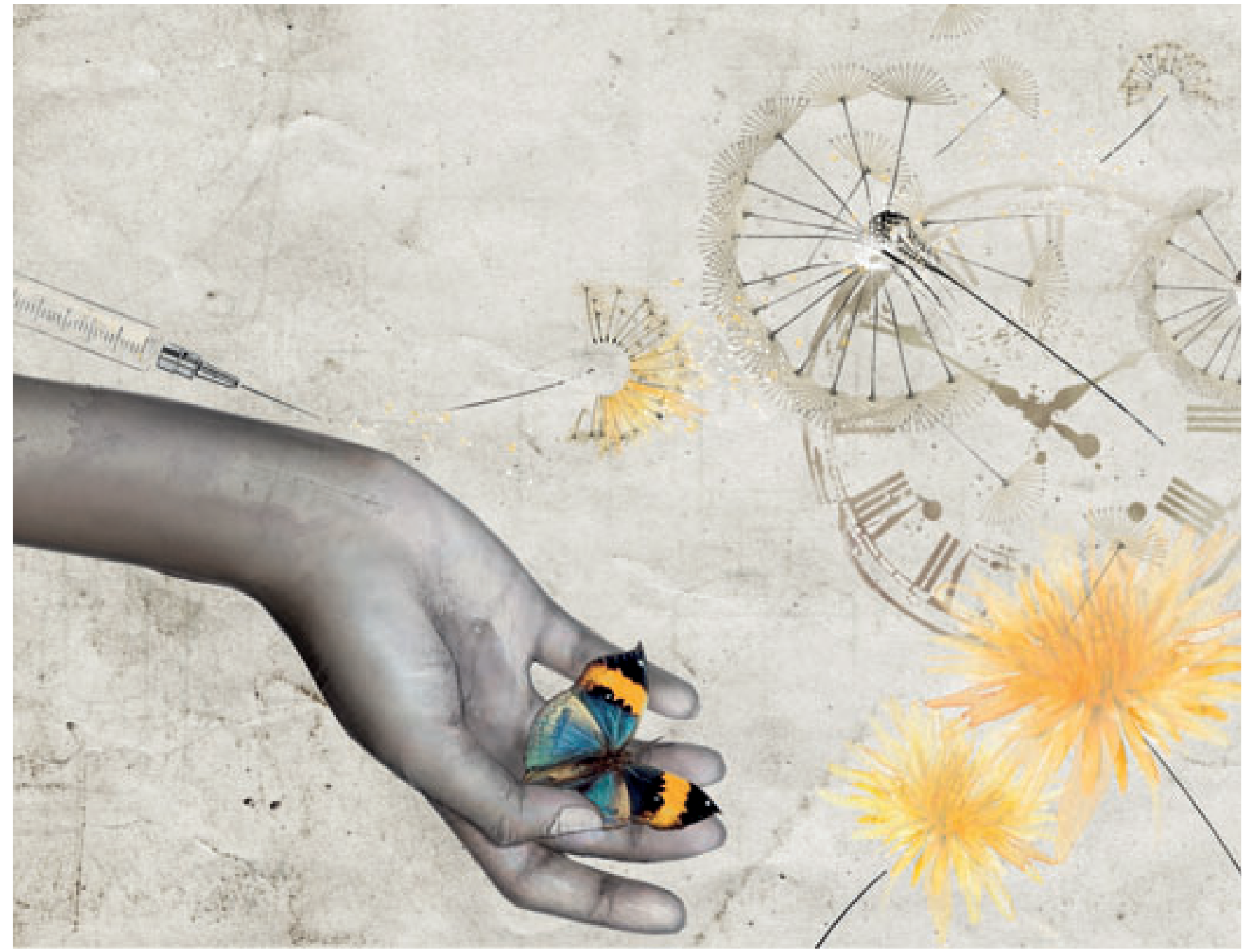

Illustrasjon Elin Karlsnes

syk (21). En nyere lærebok i medisinsk etikk for helsearbeidere kommer også med denne feilinformasjonen (22). Verken den nederlandske eller den belgiske eutanasiloven har et slikt krav $(19,20,23)$.

Ved legeassistert selvmord får pasienten utskrevet en dødelig dose barbiturater av sin lege og tar disse selv. Dette er lovlig i Nederland, Belgia, Luxembourg, Sveits og Oregon, Washington og Montana i USA. Bare i de tre amerikanske delstatene må pasienten være terminalt syk, definert som maksimalt seks måneders forventet levetid (24). Sveits er videre i en særstilling ettersom også legfolk kan assistere ved pasienters selvmord dersom det gjøres av «uegennyttige» grunner (25).

Felles for eutanasi og legeassistert selvmord er at pasienten dør av medikamenter gitt i den hensikt å ta liv, ikke av grunnsykdommen slik tilfellet er ved behandlingsbegrensning. Det er dermed snakk om fremprovosert, unaturlig død, noe som skal stå i dødsattesten i Nederland $(12,20)$. Dette betyr også at eutanasi ikke er noen form for behandling, selv om det er en medisinsk handling (18). En begrepskonstruksjon som «eutanasibehandlingen» er derfor meningsløs (26).

\section{Andre tiltak i livets sluttfase}

Følgende er medisinske handlinger som faller utenfor kategoriene eutanasi og legeassistert selvmord (18):

a. Ikke starte eller avslutte livsforlengende behandling som anses som uforholdsmessig skadelig eller nytteløs/hensiktsløs.

b. Lindring av plager med opioder eller sedativer som har en potensielt livsforkortende effekt.

c. Lindrende/terminal sedering - dvs. reduksjon av bevissthetsnivået eller induksjon av koma når døden er nær forestående.

d. Overbehandling og underbehandling (feilbehandling) med potensielt livsforkortende effekt.

e. Ikke-frivillig medisinsk drap - dvs. på pasienter som er inkompetente/ikke har fri vilje; eksempelvis alvorlig funksjonshemmede eller skadede nyfødte, personer med avansert demens, og dem med alvorlig hjerneskade. f. Ufrivillig medisinsk drap - dvs. på pasienter som er kompetente/har fri vilje og som ikke har bedt om eutanasi, men som likevel gis dødelige injeksjoner.

De to sistnevnte kategoriene er i prinsippet mord i henhold til nederlandsk straffelov (20). Men ikke nødvendigvis i praksis; jf. Groningen-protokollen som regulerer infanticid innen neonatologi $(20,27)$. Enkelte nederlandske pediatere har feilaktig kalt e. for «eutanasi» av nyfødte (27). Et eksempel på f. er legen Wilfred van Oijen, som høyesterett i 2002 dømte for mord. Ikke bare manglet det en forespørsel om eutanasi fra hans pasient; hun hadde til og med gjort det klart at hun ikke ønsket å dø (20).

\section{Sluttbetraktning}

De senere tiår har det skjedd viktige lovendringer når det gjelder eutanasi og legeassistert selvmord i flere land. Storbritannia kan bli neste land ut. I Norge fattet Fremskrittspartiet i 2009 et prinsippvedtak om å arbeide for lovendring (28). Den boksta- 
velig talt livsviktige legaliseringsdebatten må være basert på presis, logisk, konsistent og lett forståelig begrepsbruk.

\section{Lars Johan Materstvedt (f. 1960)}

er dr.art. og professor ved Filosofisk institutt. Norges teknisk-naturvitenskapelige universitet (NTNU). Tidligere forsker i Kreftforeningen. Var leder av The Ethics Task Force on Palliative Care and Euthanasia, European Association for Palliative Care (EAPC). Akademisk hjemmeside: www.materstvedt.net

Ingen oppgitte interessekonflikter.

\section{Reidun Førde (f. 1950)}

er dr.med. og professor ved Senter for medisinsk etikk, Universitetet i Oslo. Har arbeidet i mange år som kliniker, og var leder av Rådet for legeetikk i Legeforeningen 1998-2005. Leder av arbeidsgruppen som forfattet Nasjonal veileder for beslutningsprosesser for begrensning av livsforlengende behandling hos alvorlig syke og døende, Helsedirektoratet 2009.

Ingen oppgitte interessekonflikter.

\section{Litteratur}

1. Etiske regler for leger. Den norske legeforening Vedtatt av landsstyret 1961 med endringer, senest 2002. www.legeforeningen.no/id/485.1 (1.9.2011).

2. Husabø EJ. Rett til sjølvvalt livsavslutning? Oslo: Ad Notam Gyldendal, 1994.

3. Næss A. En del elementære logiske emner. Oslo: Universitetsforlaget, 1975

4. Materstvedt LJ, Førde R, Kaasa S et al. Eutanasi definisjonsmessige, etiske og kliniske betraktninger i et internasjonalt perspektiv. I: Kaasa S, red.
Palliasjon. Nordisk lærebok. Oslo: Gyldendal Akademisk, 2007: 153-78.

5. Førde R, Aasland OG, Steen PA. Medical end-oflife decisions in Norway. Resuscitation 2002; 55: 235-40.

6. Kimsma GK. Euthanasia and euthanizing drugs in the Netherlands. I: Battin MP, Lipman AG, red. Drug use in assisted suicide and euthanasia. New York: Havorth Press, 1996: 193-210.

7. Kimsma GK, van Leeuwen E. Comparing two euthanasia protocols: the Free University of Amsterdam Academic Hospital and the Medical Center of Alkmaar. I: Thomasma DC, KimbroughKushner T. Kimsma GK et al, red. Asking to die. Inside the Dutch debate about euthanasia. Dordrecht: Kluwer Academic, 1998: 115-33.

8. Onwuteaka-Philipsen BD, van der Heide A, Koper $D$ et al. Euthanasia and other end-of-life decisions in the Netherlands in 1990, 1995, and 2001. Lancet 2003; 362: 395-9

9. van der Heide A, Onwuteaka-Philipsen BD, Rurup $\mathrm{ML}$ et al. End-of-life practices in the Netherlands under the Euthanasia Act. N Engl J Med 2007; 356: $1957-65$.

10. European Association for Palliative Care (EAPC) www.eapcnet.eu (1.9.2011).

11. Materstvedt LJ, Clark D, Ellershaw J et al; EAPC Ethics Task Force. Euthanasia and physician-assis ted suicide: a view from an EAPC Ethics Task Force. Palliat Med 2003; 17: 97-101, discussion 102-79.

12. Griffiths J, Bood A, Weyers H. Euthanasia and law in the Netherlands. Amsterdam: Amsterdam University Press, 1998.

13. Almindelig borgerlig Straffelov (Straffeloven). www.lovdata.no/all/nl-19020522-010.html (1.9.2011).

14. van Marwijk H, Haverkate I, van Royen P et al. Impact of euthanasia on primary care physicians in the Netherlands. Palliat Med 2007; 21: 609-14.

15. Hume D. A treatise of human nature. Selby-Bigge LA, red. Oxford: Oxford University Press, 1958.

16. Materstvedt LJ. What is this thing called medical ethics? A Kantian interpretation. I: Carson SG Knowles J, Myskja BK, red. Kant: here, now, and how. Essays in honour of Truls Wyller. Paderborn: mentis Verlag GmbH, 2011: 207-33.

17. Kimsma GK. Death by request in The Netherlands: facts, the legal context and effects on physicians, patients and families. Med Health Care Philos 2010; 13: 355-61.

18. Materstvedt LJ, Bosshard G. Euthanasia and physician-assisted suicide. I: Hanks G, Cherny N, Christakis $\mathrm{N}$ et al, red. Oxford textbook of palliative medicine, 4. utg. Oxford: Oxford University Press, 2010: $304-19$.

19. Termination of Life on Request and Assisted Suicide (Review Procedures) Act 2002 www.healthlaw.nl/wtlovhz_eng.pdf (1.9.2011).

20. Griffiths J, Weyers H, Adams M, red. Euthanasia and law in Europe. Oxford: Hart Publishing. 2008

21. Materstvedt LJ, Førde R. Feil om eutanasi. Tidsskr Nor Legeforen 2009; 129: 121

22. Lynöe N, Juth N. Medicinska etikens ABZ. Stockholm: Liber, 2009

23. Belgium - euthanasia act of May 28, 2002. www.kuleuven.ac.be/cbmer/ viewpic. php?LAN=E\&TABLE=DOCS\&ID=23 (1.9.2011).

24. The Oregon Death with Dignity Act 1997. http://public.health.oregon.gov/ PROVIDERPARTNERRESOURCES/ EVALUATIONRESEARCH/ DEATHWITHDIGNITYACT/Pages/ors.aspx (1.9.2011).

25. Bosshard G. Switzerland. I: Griffiths J, Weyers H, Adams $M$, red. Euthanasia and law in Europe. Oxford: Hart Publishing, 2008: 463-81.

26. Lynöe N, Juth N. Hur ska man definiera dödshjälp? Tidsskr Nor Legeforen 2011; 131: 443.

27. Verhagen E, Sauer PJ. The Groningen protocol euthanasia in severely ill newborns. $N$ Engl J Med 2005; 352: 959-62.

28. Hoel PA. Frp første parti for aktiv dødshjelp. Vårt Land, 23.5.2009. www.vl.no/samfunn/ article12927.zrm (1.9.2011).

Mottatt 3.8. 2011, første revisjon innsendt 19.8. 2011, godkjent 25.8. 2011. Medisinsk redaktør

Trine B. Haugen. 